\title{
Guns in Intimate Partner Violence: Comparing Incidents by Type of Weapon
}

\author{
Susan B. Sorenson
}

\begin{abstract}
Objective: The goal of this study was to assess the frequency, nature, and outcome of weapon use in intimate partner violence (IPV) and to assess compliance with related gun policies.

Methods: Data were drawn from forms police are mandated to complete at the scene of IPV in the fifth largest U.S. city during 2013. Proportions were calculated and odds ratios were adjusted for demographic and contextual characteristics and a Bonferroni correction for multiple statistical tests was applied.

Results: Of the 35,413 incidents, 6,573 involved hands, fists, or feet, and 1,866 involved external weapons of which 576 were guns. Most incidents were male-on-female: $63.4 \%$ (no weapon), $77.4 \%$ (bodily weapon), 50.2\% (nongun external weapon), and $79.5 \%$ (gun). Guns were used most often to threaten the partner $(69.1 \%$ ). When a gun (vs. bodily or nongun external weapon) was used, IPV victims were less likely to have visible injuries (adjusted odds ratio $[\mathrm{AOR}]=0.64$ and 0.23 , respectively) — offenders were less likely to have pushed or shoved, grabbed, punched, or kicked the victim - but (victims) were more likely to be frightened ( $\mathrm{AOR}=3.13$ and 1.49 , respectively).

Conclusions: Weapon use of any type by an intimate partner is associated with a wide range of violent offender behavior and multiple negative outcomes for victims. The use of a gun has implications that include, but go beyond, physical injury of the victim. Documentation of the enforcement of state law regarding gun removal merits improvement, which has important implications for the evaluation of policies designed to keep guns out of the hands of abusers.
\end{abstract}

Keywords: domestic violence, firearms, guns, injury, intimate partner violence, policy

\section{Introduction}

$\mathbf{G}$ UNS FIGURE PROMINENTLY in the violent lives and deaths of women. An estimated 4.5 million U.S. women alive today have, at one time, been threatened with a gun held by their intimate partner. ${ }^{1,2}$ About 900,000 have been shot or shot at by an intimate partner. ${ }^{1,2}$ And when it comes to fatalities, women in the United States are more than twice as likely to be shot and killed by their male intimate as they are to be fatally shot, stabbed, bludgeoned, strangled, or killed in any other way by a stranger. ${ }^{3,4}$

Federal law (the 1994 Violence Against Act and the 1996 Lautenberg Amendment) prohibits persons under certain domestic violence restraining orders and persons convicted of a domestic violence misdemeanor from purchasing and possessing firearms. Going beyond federal statute, some states engage law enforcement officers to remove guns from batterers. The scope of these laws varies substantially-some require removal, some allow it, some are specific to guns used in the incident, and some are for all guns. ${ }^{5}$ The idea of officers removing guns at the scene of intimate partner violence (IPV) has substantial public support. ${ }^{6}$ Unfortunately, we lack systematic information about the degree to which IPV gun removal laws are being implemented and enforced.

We also know relatively little about the nonfatal use of guns against an intimate partner. A recent systematic review of the literature identified 10 studies that assessed the prevalence of nonfatal gun use by an intimate partner and raised the question of whether it is limited to severe physical abuse or is used more widely as a tool of intimidation. ${ }^{7}$ Another recent review, ${ }^{8}$ summarizing research that assessed the risk of IPV given access to firearms, found that, most often, having a gun in the home was not associated with an increased risk of nonfatal IPV. ${ }^{9-11}$ In battering, however, there appears to be a link: firearm ownership has been associated with batterers' likelihood of threatening a partner with a 
gun, ${ }^{12}$ a firearm in the home has been associated with batterers' use of the gun against the partner, ${ }^{13}$ and, in a study of 199 abused pregnant women, firearm access was associated with more severe abuse. ${ }^{14}$ In a study in Canada, firearm access was associated with severity of assault but not because of firearm use $;^{15}$ a note of caution is necessary when interpreting the study findings given that only three used a firearm in the assault. The present investigation extends this prior research and expands the scope of inquiry to include policy and practice.

Using 1 year of department-mandated domestic violence forms collected by police officers at the scene of domestic violence in one of the largest U.S. cities provided an efficient way to generate population-based knowledge about guns and nonfatal IPV. We examined the frequency and nature of gun use (e.g., who used it and how), the outcome (e.g., whether injury is more or less likely if a gun is displayed; one could reasonably expect either outcome), policy relevance (i.e., whether restraining orders are associated with lower rates of gun use), and actual law enforcement practices (e.g., how often officers take custody of a gun at the scene) in incidents of IPV.

\section{Methods}

A retrospective cohort study design was employed using all, not a sample of, IPV cases to which police were called in Philadelphia during 2013. As such, it yields a complete description of nonfatal gun use in IPV to which law enforcement responded for a population of more than 1.5 million persons.

Data were drawn from the forms that the police department requires all officers to complete and file when responding to a domestic violence call for assistance. Completion of the form, in its entirety, is mandated whether or not an arrest is made.

Law enforcement uses a broad definition of domestic violence that includes all violence in families as well as incidents involving housemates. The Philadelphia Police Department received 137,867 domestic calls for assistance in 2013; a substantial number were screened out because they were deemed to be unfounded $(n=35,668)$, another type of crime $(n=18,878)$, or another type of investigation (typically investigation of a premises; $n=26,195)$, which yielded 57,126 calls. We were provided with forms for 54,476 incidents, of which 35,413 were for IPV.

The study was reviewed and approved by the Institutional Review Board of the University of Pennsylvania.

\section{Data management}

The forms, collected in hard copy, were converted via an emerging digitization technology to electronic data that could be used for research purposes. The digitizing firm reported an accuracy rate of $99 \%$. Open-ended fields (e.g., the officer's description of the incident) were coded by a team of research assistants. To ensure the quality of the coding, coders were trained on a subset of the data until their work was deemed to be of sufficient quality before they were allowed to work on the data set itself. Second, a $10 \%$ sample of each batch of 1,000 cases was double coded, feedback given to each coder, and differences were reconciled so as to maintain a high level of inter-rater reliability. And, finally, coders coded one field at a time (quality is believed to be higher if coders focus on one field at a time) so multiple passes were made through the
35,413 records. The type and status of the offender-victim relationship, injuries, and gun involvement were coded using the relationship, body map, and narrative fields of the forms.

Weapon use consisted of four categories: no weapon, bodily weapon only (hands, fists, or feet), nongun external weapon (either alone or with a bodily weapon), and gun (either alone or in conjunction with a bodily weapon, nongun external weapon, or both). Incidents were considered to have involved a gun if a gun was mentioned in the description recorded by an officer. Whether a gun was fired was noted but the definition of gun involvement (also referred to as "gun use") was not limited to shots being fired.

Gun use was classified into 1 of 11 categories: shooting the victim; shooting at but not hitting the victim; pistol whipping; threat with hostile display (e.g., "Compl. [complainant] stated her exboyfriend came over her house to see their kids and while he was there he showed the Compl. a gun and stated 'This is for you and your new boyfriend.' Then he pulled the gun out of his waist. Male left w/o incident."), threat without hostile display (e.g., "The Compl. states she's been separated from her husband for 1 year and he stated to her that if she dates someone else he will shoot her with his gun."), threat via telephone, text, or social media (e.g., "Compl. states offender [child's father] called her over the phone and stated 'I am going to come over your house with a gun and kill you'.'); gun was stolen or taken in context of IPV incident; gun was recovered or transported (e.g., while being questioned, the victim gave the police the offender's illegal gun); the offender was carrying during the incident or the gun was simply present during the incident (e.g., "Compl. states that she awoke in bed this morning with her exboyfriend (offender) on top of her choking her. He then punched her twice on the left side of her face, scratched her neck \& stated 'I'm gonna kill you bitch.' Compl. observed a blk handgun laying on the bed beside him. She screamed \& her sons came in the bedroom \& pushed the offender off her. He then fled residence via front door.'); the victim was fearful because the offender was known to have or carry a gun (e.g., "Compl. states verbal dispute over custody issues with daughter. States offender threatening and does carry a gun. The officer spoke to offenders parole officer who is issuing a warrant for his arrest for absconder. Does have number of firearms violations per p/o [parole officer]."); and no gun involvement.

The form referred to the parties as "offenders" and "complainants" rather than offenders and victims or suspects and complainants. For the sake of simplicity we refer to them as offenders and victims.

\section{Statistical analysis}

Standard simple descriptive statistics (frequencies and percentages) and a series of multivariate logistic regressions were used to address the research questions. Although some of the variables were gender linked (e.g., $87.4 \%$ of the 1,578 strangulations and $79.5 \%$ of the 576 gun-involved incidents were male-on-female), a decision was made to retain a focus on the policy implications of the research (i.e., policies are enacted without regard to gender) and, thus, offender and victim sex were treated as covariates.

Diagnostic statistics calculated before the regressions included correlations and variance inflation factors; all were 
acceptable. Multinomial (polytomous) logistic regression was used to identify demographic characteristics associated with weapon (gun and other weapon) use. The analytic technique allows for two comparisons central to the topic at hand: we compared those who used a gun versus no weapon and those who used a gun versus another weapon. The multivariate logistic regressions that followed took into account multiple demographic and situational characteristics associated with gun use. The key predictor variable of interest was whether a gun was involved.

As is common in administrative data, information was missing for a substantial minority of the incidents. When data were missing for a predictor variable, a "not ascertained" category was included in the regressions. To assess the potential effect of missing data in the outcome variable, post hoc analyses were conducted, in which cases missing outcome variable data were dropped and the regressions run again. The results of the two regressions were compared and, in each, the findings were substantively and statistically similar; the regressions using the "not ascertained" categories are reported herein.

The data comprise the population of all calls for police assistance in one city for 1 year and, as such, statistical tests of significance and confidence intervals (CIs) are not indicated. Nevertheless, CIs are included for readers who find them useful. A Bonferroni correction was made to adjust for multiple tests.

\section{Results}

Of the 35,413 IPV incidents, 8,439 (23.8\%) involved a weapon; $6,573(18.6 \%)$ involved hands, fists, or feet; and $1,866(5.3 \%)$ involved an external weapon (i.e., a weapon other than hands, fists, or feet). Of the latter, $576(30.9 \%)$ were guns, that is, $1.6 \%$ of all incidents involved a gun. Most of the incidents were male-on-female: $63.4 \%, 77.4 \%, 50.2 \%$, and $79.5 \%$ for incidents involving no weapon, a bodily weapon, a nongun external weapon, and a gun, respectively.

The 1,290 nongun external weapons included a wide variety of available objects (ash tray, baseball bat, bleach, brick, cell phone, chair, knife, shoe, table leg, umbrella, etc.); about $15 \%$ were knives or items that could be used as a knife (box cutter, razor, scissors, etc.). Of the 576 guns, more than half $(54.0 \%)$ were reported to be simply "a gun" or to have a limited description (e.g., silver gun, 0.22 caliber). More than one-third (38.2\%) were handguns; reports of long guns (rifles and shotguns) and other guns (nearly all were stun guns) were in the single digits $(3.8 \%$ and $4.0 \%$, respectively).

\section{How guns were used}

A gun or guns were physically present in two-thirds (389 of 576) of the gun-involved incidents (Table 1). Guns were used most often $(69.1 \%)$ to threaten or intimidate the intimate partner; the gun was brandished in $42.4 \%$ of the gun-involved incidents, and the offender threatened to shoot the victim but did not display a gun in $26.7 \%$ of the incidents. About 1 in 20 $(5.7 \%)$ of the victims in gun-involved incidents was pistol whipped. The offender shot the gun in about 1 in $10(9.9 \%)$ of the gun-involved incidents; in $3.0 \%$ of the gun-involved incidents an offender shot and hit the victim.

The remaining $15.3 \%$ of the gun-involved incidents included circumstances in which the gun was physically pres-
Table 1. Nature of Gun Involvement in Intimate Partner Violence Cases $(N=576)$

\begin{tabular}{|c|c|c|}
\hline & $\mathrm{n}$ & $\%$ \\
\hline \multicolumn{3}{|l|}{ Shot or pistol whipped $(n=90 ; 15.6 \%)$} \\
\hline Shot gun (victim not hit) & 40 & 6.9 \\
\hline Hit victim with gun (pistol whipped) & 33 & 5.7 \\
\hline Shot gun (victim hit) & 17 & 3.0 \\
\hline \multicolumn{3}{|l|}{ Threatened $(n=398 ; 69.1 \%)$} \\
\hline $\begin{array}{l}\text { Brandished/threatened in person } \\
\text { (gun shown) }\end{array}$ & 244 & 42.4 \\
\hline $\begin{array}{l}\text { Threatened in person (no gun shown) } \\
\text { to shoot }\end{array}$ & 102 & 17.7 \\
\hline Threatened via phone/email/text to shoot & 52 & 9.0 \\
\hline \multicolumn{3}{|l|}{ Other $(n=88 ; 15.3 \%)$} \\
\hline $\begin{array}{l}\text { Victm fearful because offender known } \\
\text { to have or carry gun }\end{array}$ & 33 & 5.7 \\
\hline Just there during the incident/was carrying & 24 & 4.2 \\
\hline Gun stolen/taken in context of IPV incident & 16 & 2.8 \\
\hline Gun recovered or transported (not used) & 15 & 2.6 \\
\hline
\end{tabular}

IPV, intimate partner violence.

ent but not used (9.6\%). These cases were a mix of incidents in which a gun was recovered or in which the gun could and might have been used but was not (e.g., the incident was interrupted). In the remaining $5.7 \%$ of the incidents considered to involve a gun, the victim was fearful because the offender was known to have or to carry a gun. Whether to include in the analysis these 33 cases in which the victim feared the possibility of gun use would depend largely on the goal of the research. They might not be included if the analysis was conducted from a criminal charges (law enforcement) perspective. They likely would be included if the purpose was to elucidate the experience of the victim. Both perspectives are relevant here. Analyses were conducted with all cases in which a gun was mentioned and, to test the robustness of the findings and the relevance of the "fearful" cases, with the latter being recoded as "no weapon involved." The direction, magnitude, and statistical significance of the two sets of findings were consistent. Thus, the decision was made to include the "fearful" cases as "gun involved" in the analyses reported herein.

\section{Who used guns}

Several demographic and contextual characteristics were used to examine the correlates of gun use: the sex, race, and ethnicity of the victim and offender; the nature of their relationship; whether the offender was on probation, had a pending criminal case, or had a history of substance abuse; whether witnesses (including children) were present; and whether there was a history of IPV, prior IPV reports had been made to police, and a restraining order was ever issued.

When these covariates were taken into account in a multinomial (polytomous) logistic regression, the use of a gun (vs. no weapon) was more common when the offender was male, had a history of substance abuse, and was on probation (adjusted odds ratio $[\mathrm{AOR}]=1.75,1.68$, and 1.64 , respectively), when the victim was non-Hispanic Black or Hispanic, the relationship had ended, and witnesses were present $(\mathrm{AOR}=2.11$, $1.73,1.48$, and 3.13 , respectively). These and all other findings reported for the analysis of who used a gun are statistically 
significant at $p<0.05$. Gun use (vs. no weapon) also was more common when there was a history of IPV $(\mathrm{AOR}=1.54)$ and less common if a domestic violence restraining order of any type had ever been issued (AOR $=0.73)$. The use of a gun (vs. another weapon) was more common when the offender was male (AOR =2.72), the victim was female or non-Hispanic Black $(\mathrm{AOR}=2.32$ and 1.74, respectively), the couple had ever been married, was breaking up, and the relationship had ended $(\mathrm{AOR}=1.98,4.27$, and 3.50, respectively), and less common when there was a history of domestic violence $(\mathrm{AOR}=0.64)$. The victim's age (mean $=34.1$ years $)$ was important for gun versus no weapon: for every decade of victim age, the odds of using a gun (vs. no weapon) decreased by $20 \%$ $(\mathrm{AOR}=0.98)$. The offender's age (mean $=34.5$ years) was important for gun versus other weapon: for every decade of offender age, the odds of using a gun (vs. other weapon) decreased by $20 \%(\mathrm{AOR}=0.98)$.

\section{Behaviors and outcomes}

Aggressive offender behavior-pushing and shoving, grabbing, pulling hair, slapping, punching, kicking, biting, stabbing, and strangling-generally was more common when hands, fists, or feet or a nongun weapon rather than a gun was used. As shown in Table 2, sometimes the differences were substantial. For example, offenders who used a nongun weapon or a bodily weapon only were one-and-a-half to two times as likely to have punched the victim than when a gun was used (34.0\% and $46.1 \%$, respectively, vs. $21.0 \%)$. When demographic and incident characteristics were taken into account (see lower half of Table 2), the general pattern of findings became more pronounced. For example, continuing with "punched," we see that offenders who used their hands, fists, or feet were nearly three-and-a-half times as likely and those who used a nongun external weapon were more than twice as likely to have punched their victims as did offenders who used a gun.

Table 3, which reports findings for all four weapon use categories, documents that all of the listed offender behaviors-threatened, stalked, imprisoned, injured children, broke in, threw objects, damaged property, and violated a protection from abuse order-differed statistically among the four groups. When demographic and incident characteristics were taken into account, the comparisons between no weapon and gun were statistically significant: offenders who did not use a weapon were substantially less likely to have engaged in the behaviors. These analyses also indicated that there were no statistical differences by the four types of weapon use as to whether the offender violated a protection from abuse order. Offenders who used a bodily weapon (vs. a gun) and a nongun external weapon (vs. a gun) largely did not differ in the listed behaviors, either.

A notable exception is the finding that threats were less common when a gun was not used. (The inverse of the obtained AORs makes the magnitude of the differences more accessible, thus, the inverse of the AORs obtained in the statistical analysis and reported in Tables 3-5 is presented in the text.) Offenders were substantially more likely to threaten their victims when they were using a gun rather than no weapon $(\mathrm{AOR}=34.22 ; 99.86 \% \mathrm{CI}=24.28-48.22)$, their hands, fists, or feet $(\mathrm{AOR}=20.98,99.86 \% \mathrm{CI}=14.72-29.91)$, or a nongun weapon $(\mathrm{AOR}=9.36,99.86 \% \mathrm{CI}=6.23-14.06)$.

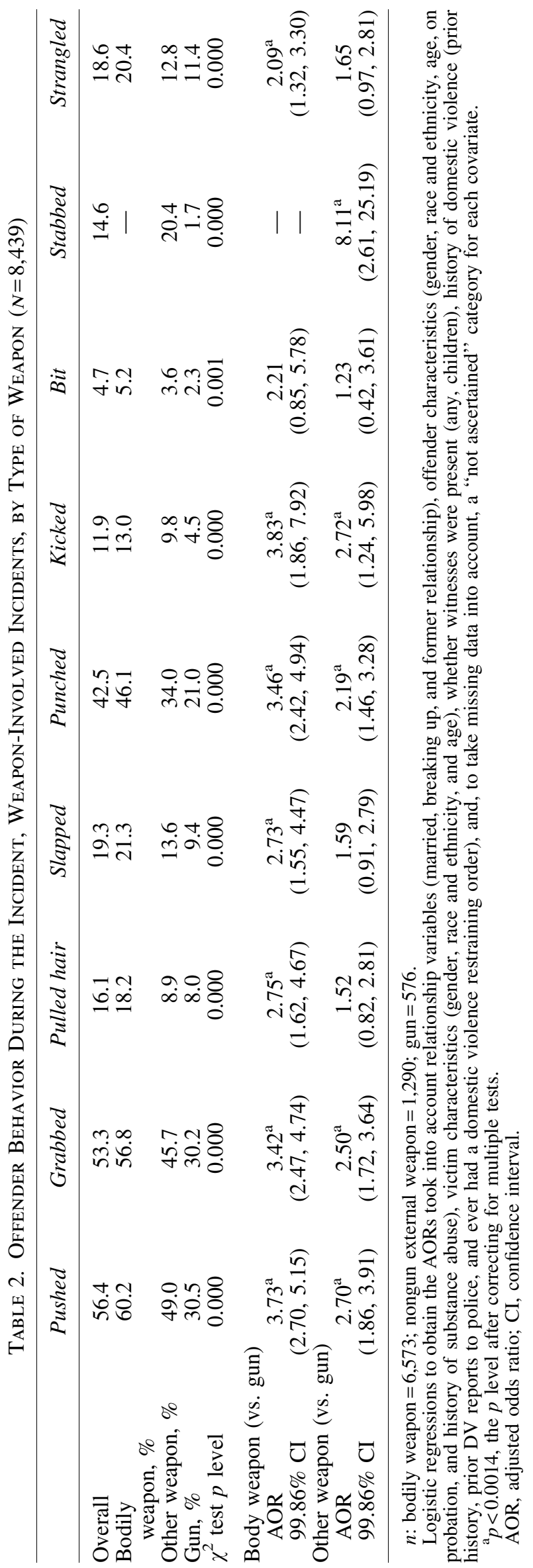


Table 3. Offender Behavior During the Incident, All Incidents, By Weapon Involvement $(N=35,413)$

\begin{tabular}{|c|c|c|c|c|c|c|c|c|}
\hline & Threatened & Stalked & Imprisoned & $\begin{array}{l}\text { Injured } \\
\text { children }\end{array}$ & Broke in & $\begin{array}{l}\text { Threw } \\
\text { objects }\end{array}$ & $\begin{array}{l}\text { Damaged } \\
\text { property }\end{array}$ & $\begin{array}{c}\text { Violated } \\
\text { PFA }\end{array}$ \\
\hline Overall & 9.3 & 2.1 & 0.8 & 0.7 & 1.5 & 4.9 & 7.2 & 5.0 \\
\hline No weapon, \% & 6.6 & 1.5 & 0.1 & 0.3 & 0.8 & 2.0 & 4.5 & 4.6 \\
\hline Bodily weapon, \% & 12.4 & 4.2 & 3.2 & 2.2 & 3.7 & 11.2 & 14.9 & 6.7 \\
\hline Other weapon, \% & 21.1 & 2.8 & 3.1 & 0.6 & 3.9 & 32.8 & 22.3 & 5.2 \\
\hline Gun, \% & 74.0 & 5.9 & 2.3 & 1.7 & 3.6 & 9.0 & 11.4 & 7.5 \\
\hline$\chi^{2}$ test $p$ level & 0.000 & 0.000 & 0.000 & 0.000 & 0.000 & 0.000 & 0.000 & 0.000 \\
\hline \multicolumn{9}{|c|}{ No weapon (vs. gun) } \\
\hline AOR & $0.03^{\mathrm{a}}$ & $0.39^{\mathrm{a}}$ & $0.06^{\mathrm{a}}$ & $0.18^{\mathrm{a}}$ & $0.39^{\mathrm{a}}$ & $0.26^{\mathrm{a}}$ & $0.50^{\mathrm{a}}$ & 0.64 \\
\hline $99.86 \%$ CI & $(0.03,0.04)$ & $(0.20,0.73)$ & $(0.02,0.18)$ & $(0.06,0.55)$ & $(0.17,0.88)$ & $(0.15,0.45)$ & $(0.31,0.79)$ & $(0.32,1.26)$ \\
\hline \multicolumn{9}{|c|}{ Body weapon (vs. gun) } \\
\hline AOR & $0.05^{\mathrm{a}}$ & 1.00 & 1.25 & 1.25 & 1.54 & 1.51 & 1.48 & 1.48 \\
\hline $99.86 \% \mathrm{CI}$ & $(0.03,0.07)$ & $(0.53,1.88)$ & $(0.49,3.21)$ & $(0.43,3.67)$ & $(0.69,3.43)$ & $(0.88,2.57)$ & $(0.93,2.35)$ & $(0.73,3.00)$ \\
\hline \multicolumn{9}{|c|}{ Other weapon (vs. gun) } \\
\hline AOR & $0.11^{\mathrm{a}}$ & 0.72 & 1.54 & 0.30 & 1.77 & $5.62^{\mathrm{a}}$ & $2.33^{\mathrm{a}}$ & 1.03 \\
\hline $99.86 \% \mathrm{CI}$ & $(0.07,0.16)$ & $(0.31,1.68)$ & $(0.53,4.45)$ & $(0.06,1.50)$ & $(0.70,4.46)$ & $(3.21,9.84)$ & $(1.41,3.84)$ & $(0.44,2.42)$ \\
\hline
\end{tabular}

$n$ : no weapon $=26,974$; bodily weapon $=6,573$; nongun external weapon $=1,290 ;$ gun $=576$.

Logistic regressions to obtain the AORs took into account relationship variables (married, breaking up, and former relationship), offender characteristics (gender, race and ethnicity, age, on probation, and history of substance abuse), victim characteristics (gender, race and ethnicity, and age), whether witnesses were present (any, children), history of domestic violence (prior history, prior DV reports to police, and ever had a domestic violence restraining order), and, to take missing data into account, a "not ascertained" category for each covariate. ${ }^{a} p<0.0014$, the $p$-level after correcting for multiple tests.

PFA, protection from abuse (restraining) order.

Chi-square analyses indicated that the officers' observations of the victim differed by the type of weapon used; each comparison was statistically significant (Table 4). However, the multivariate analyses that took into account multiple other variables, including whether the victim had been punched, kicked, etc., documented few statistically significant differences.

Two sets of findings merit note, fear and visible injury. Although victims against whom a gun was used were less likely to have visible physical injuries (gun vs. bodily weapon: $\mathrm{AOR}=0.64 ; 99.89 \% \mathrm{CI}=0.42-0.97$; gun vs. nongun external weapon: $\mathrm{AOR}=0.23 ; 99.89 \% \mathrm{CI}=0.25-0.37)$, they were substantially more likely to be frightened (gun vs. bodily weapon: $\mathrm{AOR}=3.08 ; 99.89 \% \mathrm{CI}=2.19-4.32$; gun vs. nongun external weapon: $\mathrm{AOR}=1.50 ; 99.89 \% \mathrm{CI}=1.01-$ 2.22). (Please note that, for clarity, the inverse of the AORs obtained in the statistical analysis and reported in Table 4 is presented here.)

Observations of the scene and the offender also differed statistically according to chi-square tests but fewer comparisons were statistically significant in the multivariate analyses (Table 5). Property damage and disarray were less common when no weapon was used and more common when a nongun weapon (vs. gun) was involved.

Of particular note is the finding that offenders who used a gun were more likely to have left before officers arrived than offenders who used no weapon, a bodily weapon, or a nongun external weapon $(71.4 \%$ vs. $45.9 \%, 58.8 \%$, and $49.1 \%$, respectively). The finding held when covariates were taken into account: offenders who used a gun were more likely to have fled (gun vs. no weapon: $\mathrm{AOR}=2.65 ; 99.86 \% \mathrm{CI}=1.91-3.66$; gun vs. bodily weapon: $\mathrm{AOR}=1.47 ; 99.86 \% \mathrm{CI}=1.05-2.06$; gun vs. nongun external weapon: $\mathrm{AOR}=1.84 ; 99.86 \% \mathrm{CI}=1.26-2.68$ ).

If the offender was on the scene, once covariates were taken into consideration, his or her behavior was similar regardless of weapon use with one exception: offenders who used a gun were substantially more likely to be threatening when the police were present than were offenders who did not use a weapon $(\mathrm{AOR}=33.71 ; 99.86 \% \mathrm{CI}=18.30-62.12)$ or who used a bodily weapon $(\mathrm{AOR}=2.81 ; 99.86 \% \mathrm{CI}=1.56$ 5.04). Those who used a gun and those who used another (nongun) external weapon did not differ statistically in their threatening behavior on the scene $(\mathrm{AOR}=1.61 ; 99.86 \%$ $\mathrm{CI}=0.84-3.08)$.

\section{Intervention}

Table 6 reports what officers did at the scene. Officers were substantially more likely to arrest an offender if a weapon had been used; this finding held regardless of whether the offender was on the scene. Offenders who did not use any weapon were substantially less likely to be arrested than those who used a gun, whereas the odds of being arrested were not statistically different for those who used a bodily weapon rather than a gun. The odds of being arrested were higher for those who used a nongun external weapon (vs. a gun). Thus, weapon-wielding offenders were substantially more likely to be immediately arrested and removed from the scene for an unknown time.

In terms of other intervention and prevention, officers were roughly equally likely to give information about resources to victims regardless of weapon involvement; none of the multivariate comparisons regarding information giving was statistically significant. Other on-the-scene officer behaviors were more common when the offender used a gun (vs. no weapon): Officers were more likely to take statements, check the statewide registry of restraining orders, and to check whether the offender and victim had a permit to carry a gun. Regardless of whether the offender was present, the odds of the victim being transported to a hospital (a process often facilitated by the officers) were substantially higher if the offender had used a bodily weapon $(\mathrm{AOR}=2.69 ; 99.86 \%$ 


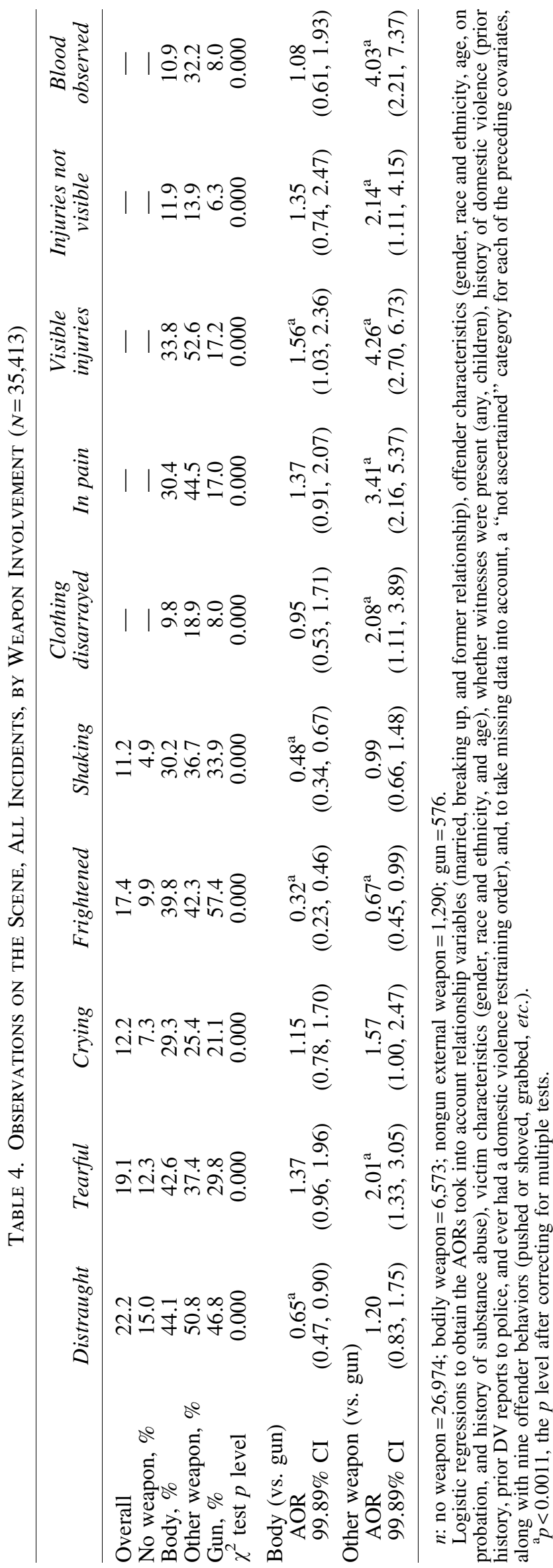

$\mathrm{CI}=1.35-5.33)$ or a nongun external weapon $(\mathrm{AOR}=7.23$; 99.86\% CI $=3.56-14.67$ ) rather than a gun.

\section{Policy-related findings}

Officers noted that a total of $5.9 \%$ of those who used a gun were under court supervision (on probation or had a criminal case pending) compared with $3.1 \%$ of those who used a nongun external weapon, $3.9 \%$ of those who used a bodily weapon, and $1.9 \%$ of those who did not use a weapon. Officers recorded Uniform Crime Reporting incident codes that are a felony or are likely a felony (e.g., certain robberies) for 309 of the incidents involving a gun. If the offenders were found guilty, they would be prohibited by federal law from purchasing and possessing a firearm.

Pennsylvania law, passed in October 2005, mandates the removal of weapons under certain circumstances. The law requires the arresting officer to "seize all weapons used by the defendant in the commission of the alleged offense" if a probable-cause arrest (i.e., without a warrant) can be made under certain statutes (e.g., simple assault) and the officer has observed "recent physical injury to the victim or other corroborative evidence" [18 Pa. Cons. Stat. $\S 2711(b)]$. According to the officers' reports, of the 2,822 persons who were arrested, a gun or guns were removed from $6(0.3 \%)$ of the 2,079 who did not use a weapon, $2(0.3 \%)$ of the 594 who used a nongun weapon, and $62(41.6 \%)$ of the 149 who used a gun in the incident. Limiting analysis to the 29 incidents in which an offender was arrested having pistol-whipped the victim or shot a gun (e.g., eliminating cases in which a victim said a gun was brandished) and the offender was arrested, responding officers reported that they removed a gun in $44.8 \%$ of the incidents.

Although federal law prohibits the possession of firearms by persons subject to certain domestic violence restraining orders, Pennsylvania state law provides the courts discretion as to whether a firearms prohibition is imposed. ${ }^{5}$ Whether the courts ordered relinquishment and whether the restrained person complied with a relinquishment order are not information available on the forms used by the police department. In $5(9.6 \%)$ of the 52 incidents in which a gun was used and a protection from abuse order was active, officers reported removing a gun or guns.

\section{Discussion}

A firearm was present in about $5 \%$ of the 805,700 intimate partner assaults reported by women respondents in the 20022011 National Crime Victimization Surveys. ${ }^{16}$ By contrast, in Philadelphia in 2013, a gun was involved in $1.6 \%$ and physically present in $1.1 \%$ of the 35,413 intimate partner calls for assistance $(1.9 \%$ and $1.3 \%$, respectively, of the calls in which the victims were women). Findings indicate that guns were used most often (more than two-thirds of the time) to threaten an intimate partner; in about $15 \%$ of the incidents with a gun, the offender used the gun to hit, shoot at, or shoot the victim.

In general, violent behaviors by the offender (punching, kicking, etc.) were most common when a bodily weapon alone (hands, fists, or feet) was used, followed by when a nongun external weapon was used, and least common when a gun was used. The use of an external weapon that was not a gun was associated with the most victim distress, pain, and 
Table 5. Observations on the Scene, All Incidents, by Weapon Involvement $(N=35,413)$

\begin{tabular}{|c|c|c|c|c|c|c|c|c|}
\hline & \multirow{2}{*}{\multicolumn{2}{|c|}{ Property }} & \multicolumn{6}{|c|}{ Offender } \\
\hline & & & \multirow{2}{*}{$\begin{array}{l}\text { Left the } \\
\text { scene }\end{array}$} & \multicolumn{5}{|c|}{ If present } \\
\hline & $\begin{array}{l}\text { Furniture } \\
\text { disarrayed }\end{array}$ & $\begin{array}{l}\text { Property } \\
\text { damaged }\end{array}$ & & Polite & Cooperative & Apologetic & Angry & Threatening \\
\hline Overall & 3.6 & 7.6 & 48.9 & 46.9 & 56.8 & 15.4 & 26.8 & 5.5 \\
\hline No weapon, \% & 1.9 & 5.5 & 45.9 & 48.6 & 58.4 & 15.8 & 24.1 & 1.5 \\
\hline Body, \% & 7.8 & 13.3 & 58.8 & 40.5 & 50.6 & 14.3 & 36.8 & 19.5 \\
\hline Other weapon, \% & 14.8 & 20.9 & 49.1 & 37.4 & 49.2 & 11.7 & 43.4 & 27.3 \\
\hline Gun, $\%$ & 5.9 & 12.3 & 71.4 & 38.4 & 49.4 & 9.2 & 37.6 & 42.7 \\
\hline$\chi^{2}$ test $p$ level & 0.000 & 0.000 & 0.000 & 0.000 & 0.000 & 0.000 & 0.000 & 0.000 \\
\hline \multicolumn{9}{|c|}{ No weapon (vs. gun) } \\
\hline AOR & $0.39^{\mathrm{a}}$ & $0.60^{\mathrm{a}}$ & $0.38^{\mathrm{a}}$ & 1.29 & 1.42 & 1.74 & 0.67 & $0.03^{\mathrm{a}}$ \\
\hline $99.86 \% \mathrm{CI}$ & $(0.21,0.73)$ & $(0.39,0.95)$ & $(0.27,0.52)$ & $(0.74,2.24)$ & $(0.83,2.45)$ & $(0.70,4.35)$ & $(0.38,1.18)$ & $(0.02,0.05)$ \\
\hline \multicolumn{9}{|l|}{ Body (vs. gun) } \\
\hline AOR & 1.40 & 1.28 & $0.68^{\mathrm{a}}$ & 0.94 & 1.00 & 1.53 & 1.03 & $0.36^{\mathrm{a}}$ \\
\hline $99.95 \%$ CI & $(0.75,2.61)$ & $(0.82,2.02)$ & $(0.49,0.95)$ & $(0.54,1.65)$ & $(0.57,1.74)$ & $(0.61,3.86)$ & $(0.58,1.82)$ & $(0.20,0.64)$ \\
\hline \multicolumn{9}{|c|}{ Other weapon (vs. gun) } \\
\hline AOR & $2.89^{\mathrm{a}}$ & $2.07^{\mathrm{a}}$ & $0.54^{\mathrm{a}}$ & 0.89 & 1.00 & 1.39 & 1.13 & 0.62 \\
\hline $99.86 \% \mathrm{CI}$ & $(1.49,5.60)$ & $(1.26,3.41)$ & $(0.37,0.79)$ & $(0.48,1.63)$ & $(0.55,1.82)$ & $(0.52,3.75)$ & $(0.61,2.10)$ & $(0.32,1.18)$ \\
\hline
\end{tabular}

$n$ : no weapon $=26,974$; bodily weapon $=6,573$; nongun external weapon $=1,290 ;$ gun $=576$.

Logistic regressions to obtain the AORs took into account relationship variables (married, breaking up, and former relationship), offender characteristics (gender, race and ethnicity, age, on probation, and history of substance abuse), victim characteristics (gender, race and ethnicity, and age), whether witnesses were present (any, children), history of domestic violence (prior history, prior DV reports to police, and ever had a domestic violence restraining order), and, to take missing data into account, a "not ascertained" category for each covariate.

${ }^{\mathrm{a}} p<0.0014$, the $p$ level after correcting for multiple tests.

injury. Of particular note is the finding that although victims against whom a gun was used were less likely to have visible injuries, they were far more likely to have been threatened and substantially more likely to be frightened. As a whole, findings suggest that (1) persons who use a gun against their intimate partners are less intent on inflicting physical harm than are those who use another type of weapon; (2) intimates use a gun to intimidate and coerce (i.e., to increase victim compliance during an assault), which results in fewer visible injuries and greater victim fear; or (3) some combination of the two.

Even when other offender behaviors (punching, kicking, etc.) are taken into account, offenders who use a gun against an intimate partner are more likely to be gone when officers arrive and, if still present, are more likely to be threatening on the scene. Many of those who left the scene may well have taken the gun with them. If an offender had left the scene, an arrest was understandably less likely. The mandated removal of weapons when the offender was arrested, however, was reported to have occurred in fewer than half of the incidents that involved a gun. The lack of documented enforcement is notable and merits research beyond one locale. In many jurisdictions, a substantial number of arrested domestic violence offenders are released shortly after arrest, and access to a gun at that time could increase risk for victims. Additional research is needed to explore that possibility.

\section{Strengths and limitations}

A key strength of the research is that it describes all calls to police for one city for 1 year for an entire population of community-residing persons. The data, from the fifth-largest U.S. city, included a large number of incidents that allowed for the use of statistical techniques that take into account multiple victim, perpetrator, and incident characteristics along with the primary variable of interest, weapon use.

The administrative data provided an efficient and economical means to study the topic. A general population survey of a sample of residents would be needed to be able to estimate all gun use against an intimate partner. Conducting such a survey, either as a stand-alone survey or as an addition to an on-going survey, is possible yet challenging because of currently low response rates, a variety of concerns related to self-report, and the cost-benefit ratio of spending research dollars on a survey when a viable alternative exists to address a similar question. In addition, the data allowed us to describe officers' self-report of their action in terms of following the legal mandate to remove firearms when an arrest is made, an otherwise difficult phenomenon to observe.

The accuracy of the information the officers reported could not be verified. Thus, for example, we cannot ascertain whether, when an offender was arrested, a gun was present and officers did not remove it or whether officers removed a gun but did not record it. Nor can we ascertain the completeness of or potential systematic bias in the information recorded. For example, an offender may have shaken his fist at but not hit the victim and the victim not reported the action to an officer or the officer not recorded it on the form, whereas victims may have been more likely to report and the officer to record that a gun was pointed at them. The fact that offenders were more likely to be threatening on the scene as well as toward the victim suggests, however, that disproportionate victim reporting (i.e., over-reporting) of threats with a gun might not have occurred. The quantity and quality of available information can be expected to improve with further law enforcement investigation, as would be the situation for the subset of cases (not identified in the on-the-scene reports) that were assigned to detectives. 


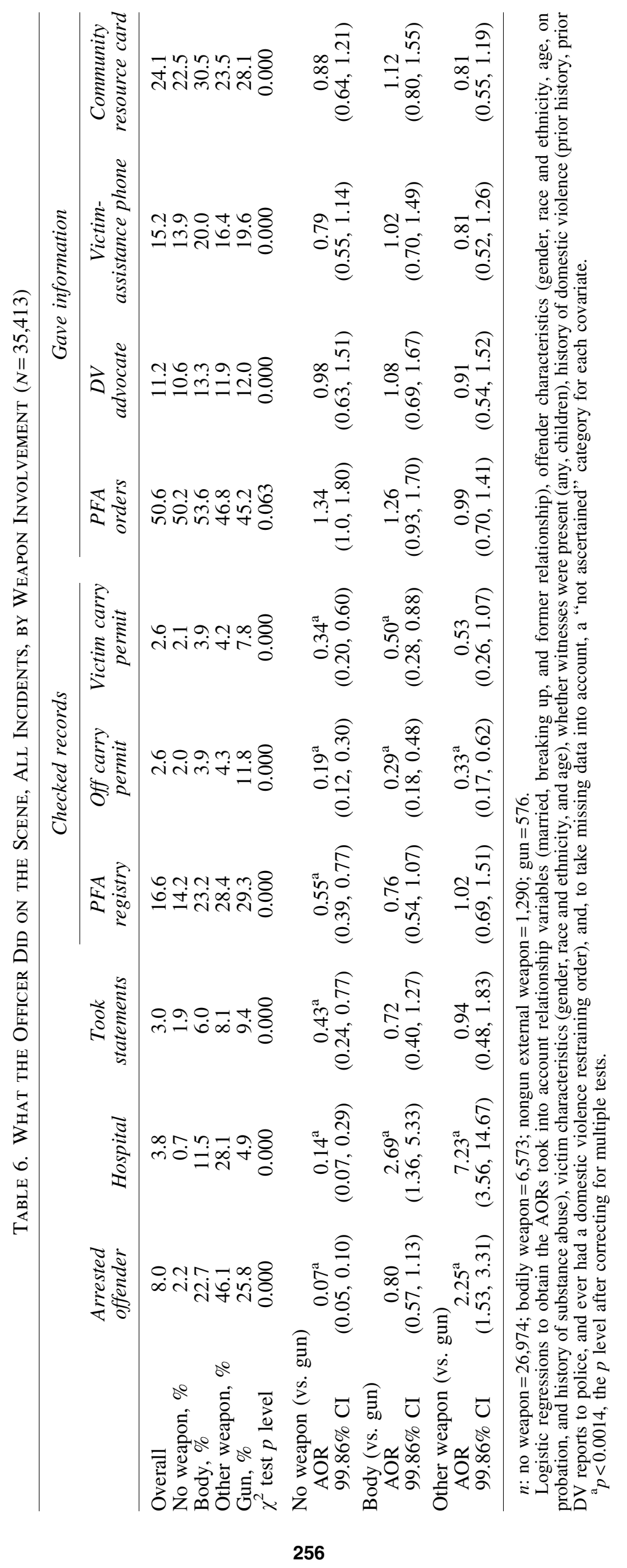


Another limitation is that the forms did not contain information about victim behavior during the incident. Given that victims were more likely to be punched, kicked, injured, etc. when a nongun weapon (vs. gun) was used, one could reasonably surmise that victims might have been more likely to try to defend themselves or fight back when a nongun weapon was used but to acquiesce when a gun was used. Or perhaps offenders using a nongun weapon were simply more intent on assaulting the victim than were offenders using a gun. Although study findings suggest these possibilities, such questions cannot be tested in the data.

\section{Implications}

Clinical care. Healthcare providers respond primarily to the health problem with which they are presented and, in the case of active battering, the acute issue likely is an injury inflicted by the abusers' hands, fists, or feet. Our findings indicate that when a weapon other than a gun is used, the risk of physical harm is higher, perhaps, in part, because the potential victim chooses to resist or fight back, resulting in further harm.

The presence of a gun might be associated with lesser injury than another weapon, but it portends ill for the woman. Guns can facilitate a condition known as coercive control, in which an abuser dominates and intimidates his intimate partner. ${ }^{17}$ Women living under chronic threat can be expected to have a high allostatic load that has been associated with multiple negative health outcomes. Inquiring about gun involvement in incidents of IPV will provide the clinician with a greater understanding of the circumstances that the woman routinely navigates.

Physicians practicing in Florida likely are aware of a 2011 state law restricting physician inquiries about guns in the home. It includes an exception for circumstances in which the physician "in good faith believes this information is relevant to the patient's medical care or safety or to the safety of others." 18 Abuse is likely one of those circumstances.

There has been relatively little discussion, let alone agreement, about what physicians should do next. Options range from nothing (record the information in the chart only) to informing the woman about laws and procedures by which her abuser can be prevented from purchasing and possessing a gun to encouraging her to get her own gun. (In terms of the latter, note that the best available research shows that women's purchase of a handgun is associated with a subsequent and lasting increase in their risk of becoming a victim of both homicide and suicide. ${ }^{19}$ )

Educating physicians about relevant laws can be helpful; for example, a recent article ${ }^{20}$ debunks the idea that physicians in some states are barred from asking about guns in the home and suggests when such questions might be most appropriate. Another recent article suggests that most patients would be receptive: a majority of individuals, including gun owners, believe that it is at least sometimes appropriate for physicians to ask about guns in the home. ${ }^{21}$ Although the process can be anticipated to be somewhat lengthy, physician organizations are encouraged to begin discussions so as to arrive at a standard of practice.

Partners in prevention. Police are the most common first responders in IPV. Victims typically call the police, and call repeatedly, in an attempt to get their partner to stop being violent. Calls for police assistance ("911" calls) typically are made long before there is a domestic violence restraining order or a domestic violence misdemeanor conviction. Thus, law enforcement work can be a useful point of intervention and prevention.

Certain potentially helpful officer actions occur, at least according to the report of the officers themselves, less often than would be ideal: officers reported that they provided about one-fourth of the victims with a community resource card (an action mandated by Department directive), one-sixth with the phone number for victim-assistance services, and one-tenth with information about the domestic violence advocate. Officers reported telling about half of the victims about protection from abuse orders, the option that would require the most effort for victims (e.g., filing a petition and appearing before a judge) but would, if certain orders are issued, prohibit the abuser from being able to legally purchase and possess a gun. And, finally, officer documentation of the enforcement of state law regarding the removal of guns at the scene can be improved.

Policy. Understanding the scope of gun possession by abusers might encourage some legislatures to extend firearm purchase and possession prohibitions to emergency restraining orders. Although a woman's risk of homicide is highest when she is trying to end the relationship, ${ }^{22}$ most state laws regarding restraining orders are consistent with federal law, which limits the prohibitions to only certain domestic violence restraining orders and emergency orders are not among them.

It is important to know how laws related to guns and IPV are implemented and enforced. Such knowledge can be used in future agency directives and legislative action. The few evaluations of the aforementioned laws designed to reduce abusers' access to guns document modest effects. ${ }^{23-26}$ Each of the investigations was limited by an inability to assess the degree to which the laws were implemented.

\section{Conclusion}

Victims of IPV against whom a gun was used were less likely to have visible injuries, were far more likely to have been threatened, and were substantially more likely to be frightened. Medicine and public health focus primarily on physical injuries (both fatal and nonfatal) to document the nature and scope of gun violence. Such a focus may need to be reconsidered if gun use in IPV is primarily a means to an end. In this situation, guns would heighten fear and compliance and likely would reduce willingness to leave or otherwise end the relationship, thus promoting chronic abuse.

\section{Acknowledgments}

The author is grateful to the Philadelphia Police Department for providing access to the data. The project was begun under Commissioner Charles Ramsey, Deputy Commissioners Nola Joyce and Kevin Bethel, and Lt. Altovise Love-Craighead and completed under Commissioner Richard Ross, Deputy Commissioner Myron Patterson, and Lt. Krista Dahl-Campbell. The author thanks the New Venture Fund and the Evelyn Jacobs Ortner Center on Family Violence for funding a portion of the work and extends appreciation to the team of assistants who coded the data: Devan Spear, Rebecca Schut, Olivia 
Webb, Lauren Ferreira Cardoso, Eleanor Thompson, and Diana Estefania Estrada-Alamo.

\section{Author Disclosure Statement}

No competing financial interests exist.

\section{References}

1. Tjaden P, Thoennes N. Extent, nature, and consequences of intimate partner violence: Findings from the National Violence Against Women Survey. Washington, DC: Department of Justice, National Institute of Justice, and Centers for Disease Control and Prevention, 2000:Report No. NCJ 181867.

2. US Census Quick Facts. United States. Available at: www .census.gov/quickfacts/table/PST045215/00 Accessed January $16,2016$.

3. Kellermann AL, Mercy JA. Men, women, and murder: Gender-specific differences in rates of fatal violence and victimization. J Trauma 1992;33:1-5.

4. Sorenson SB. Firearms use in intimate partner violence: A brief overview. Eval Rev 2006;30:229-236.

5. Law Center to Prevent Gun Violence. Domestic violence \& firearms policy summary. Available at http://smartgunlaws .org/domestic-violence-firearms-policy-summary Accessed December 14, 2015.

6. Sorenson SB. Taking guns from batterers: Public support and policy implications. Eval Rev 2006;30:361-373.

7. Sorenson SB, Schut R. Non-fatal gun use in intimate partner violence: A systematic review of the literature. Trauma Violence Abuse 2016 [Epub ahead of print].

8. Zeoli AM, Malinski R, Turchan B. Risks and targeted interventions: Firearms in intimate partner violence. Epidemiol Rev 2016;38:125-139.

9. Coker AL, Smith PH, McKeown RE, et al. Frequency and correlates of intimate partner violence by type: Physical, sexual, and psychological battering. Am J Public Health 2000;90:553-559.

10. Glass N, Perrin N, Hanson G, Bloom T, Gardner E, Campbell JC. Risk for reassault in abusive female same-sex relationships. Am J Public Health 2008;98:1021-1027.

11. Vest JR, Catlin TK, Chen JJ, Brownson R. Multistate analysis of factors associated with intimate partner violence. Am J Prev Med 2002;22:156-164.

12. Rothman EF, Hemenway D, Miller M, Azrael D. Batterers' use of guns to threaten intimate partners. J Am Med Womens Assoc 2005;60:62-68.

13. Sorenson SB, Wiebe DJ. Weapons in the lives of battered women. Am J Public Health 2004;94:1412-1417.
14. McFarlane J, Soeken K, Campbell J, Parker B, Reel S, Silva C. Severity of abuse to pregnant women and associated gun access of the perpetrator. Public Health Nurs 1998;15:201-206.

15. Folkes SEF, Hilton NZ, Harris GT. Weapon use increases the severity of domestic violence but neither weapon use nor firearm access increases the risk or severity of recidivism. J Interpers Violence 2013;28:1143-1156.

16. Catalano S. Intimate partner violence: Attributes of victimization, 1993-2011. U.S. Bureau of Justice Statistics, NCJ 243300, November 2013.

17. Stark E. Coercive control: How men entrap women in personal life. New York: Oxford University Press, 2009.

18. Kuehn BM. Battle over Florida legislation casts a chill over gun inquiries. JAMA 2015;313:1893-1895.

19. Wintemute GJ, Parham CA, Beaumont JJ, Wright M, Drake C. Mortality among recent purchasers of handguns. N Engl J Med 1999;341:1583-1589.

20. Wintemute GJ, Betz ME, Ranney ML. Yes, you can: Physicians, patients, and firearms. Ann Intern Med 2016;165: 205-213.

21. Betz ME, Azrael D, Barber C, Miller M. Public opinion regarding whether speaking with patients about firearms is appropriate: Results of a national survey. Ann Intern Med 2016;165:543-550.

22. Wilson M, Daly M. Spousal homicide risk and estrangement. Violence Vict 1993;8:3-16.

23. Bridges FS, Tatum KM, Kunselman JC. Domestic violence statutes and rates of intimate partner and family homicide: A research note. Crim Justice Policy Rev 2008;19:117-130.

24. Dugan L. Domestic violence legislation: Exploring its impact on the likelihood of domestic violence, police intervention, and arrest. Criminol Public Policy 2003;2:283-312.

25. Vigdor ER, Mercy JA. Do laws restricting access to firearms prevent intimate partner homicide? Eval Rev 2006; 30:313-346.

26. Zeoli AM, Webster DW. Effects of domestic violence policies, alcohol taxes and police staffing levels on intimate partner homicide in large U.S. cities. Injury Prev 2010; 16:90-95.

Address correspondence to: Susan B. Sorenson, PhD

School of Social Policy and Practice

University of Pennsylvania

3815 Walnut Street Philadelphia, PA 19104

E-mail: sorenson@upenn.edu 